\title{
Overweight and obesity by school socioeconomic composition and adolescent socioeconomic status: a school-based study
}

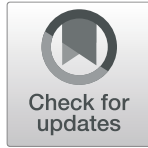

Maxime Luiggi ${ }^{1,2^{*}}$ D, Olivier Rey ${ }^{3,2}$, Maxime Travert ${ }^{2,3}$ and Jean Griffet ${ }^{2}$

\begin{abstract}
Background: The main objective of this study was to investigate the interaction effect of school socioeconomic composition (SEC) and adolescent socioeconomic status (SES) in the prevalence of overweight and obesity among a representative sample of French adolescents of the third most populous département of France.

Methods: 1038 adolescents agreed to participate (response rate: 91.4\%). They self-reported anthropomorphic variables, SES, school lunch and physical activity. The body mass index was divided into six categories according to the Center for Disease Control. Multivariable binary logistic regressions analysis without and with interaction term were performed on overweight or obesity. Models fit was compared using the Aikaike Information Criterion. Oddsratios (OR) and their 95\% accelerated-bootstrap confidence interval $(95 \% \mathrm{BCa} \mathrm{Cl})$ were computed to estimate overweight or obesity risk.
\end{abstract}

Results: $8.9 \%$ of the adolescents were overweight. 3.4\% were obese. No school-SEC effect was observed among low-SES adolescents. Medium-SES adolescents were at greater risk in low-SEC (OR $=10.75,95 \% \mathrm{BCa} \mathrm{Cl}=2.67-64.57)$ and medium-SEC $(\mathrm{OR}=5.08,95 \% \mathrm{BCa} \mathrm{Cl}=1.55-24.84)$ compared with high-SEC schools. High-SES adolescents in low-SEC schools were at greater risk compared with those in medium-SEC $(\mathrm{OR}=5.94,95 \% \mathrm{BCa} \mathrm{Cl}=1.94-17.29)$ and high-SEC schools $(\mathrm{OR}=4.99,95 \% \mathrm{BCa} \mathrm{Cl}=1.71-13.14)$. A social gradient was observed in medium-SEC $(\mathrm{OR}$ low/high $=$ $2.79,95 \% \mathrm{BCa} \mathrm{Cl}=1.22-7.41)$ and high-SEC $\left(\mathrm{OR}_{\text {low/medium }}=6.86,95 \% \mathrm{BCa} \mathrm{Cl}=1.06-5.22^{*} 10^{6}\right)$ schools.

Conclusions: Physical activity and lunch at and outside school help to understand these differences. Implications for obesity prevention initiatives are discussed.

Keywords: Weight status, Socioeconomic status, Socioeconomic composition, Physical activity, Lunch type

\section{Background}

Obesity during adolescence is a stronger predictor of obesity during adulthood than obesity in earlier ages of life $[1,2]$. Identifying adolescent obesity clusters is essential in promoting prevention initiatives, to prevent its spread through social contagion and thus reduce its short- and long-term burden [3]. Most paediatric obesity

\footnotetext{
* Correspondence: maxime.luiggi@univ-amu.fr

${ }^{1}$ Aix Marseille Univ, ADEF, Marseille, France

${ }^{2}$ Structure Fédérative d'Études et de Recherches en Éducation de Provence, FED 4238, Marseille, France

Full list of author information is available at the end of the article
}

is said to result from the interaction between susceptibility genes and unhealthy lifestyle habits such as poor nutrition, high sedentary behaviour, and insufficient physical activity (PA) [4-6].

These habits are in part shaped by the provisions and types of facilities available in peoples' living environments, for example the presence of fast-food restaurants, parks, cycling paths and sport facilities [7-9]. These environmental factors can cause overweight and obesity prevalence disparities within the same country, and even

(c) The Author(s). 2021 Open Access This article is licensed under a Creative Commons Attribution 4.0 International License, which permits use, sharing, adaptation, distribution and reproduction in any medium or format, as long as you give appropriate credit to the original author(s) and the source, provide a link to the Creative Commons licence, and indicate if changes were made. The images or other third party material in this article are included in the article's Creative Commons licence, unless indicated otherwise in a credit line to the material. If material is not included in the article's Creative Commons licence and your intended use is not permitted by statutory regulation or exceeds the permitted use, you will need to obtain permission directly from the copyright holder. To view a copy of this licence, visit http://creativecommons.org/licenses/by/4.0/ The Creative Commons Public Domain Dedication waiver (http://creativecommons.org/publicdomain/zero/1.0/) applies to the data made available in this article, unless otherwise stated in a credit line to the data. 
within the same local area when the area contains a variety of direct life environments [10].

Disadvantaged areas are specifically subject to higher prevalence of overweight and obesity due to an unfavourable environment for adopting a healthy diet and a physically active lifestyle [11-13]. Among adolescents, those living in a neighbourhood and attending a school with lower socioeconomic composition (SEC) are at greater risk of overweight and obesity [10, 14, 15]. Neighbourhood SEC was also found to be more influential than household socioeconomic status (SES) [10].

Meanwhile, in the same local environment, adolescents can develop different PA and nutritional habits and thus have different body mass index (BMI) trajectories. It is acknowledged that those with a lower household SES, in a similar local environment, will be more likely to be overweight or obese than those with a higher household SES [16]. However, as shown by one study, this household SES effect may depend on the SES of these adolescents' living environment [17]. Kim et al. (2020) showed that high-SES neighbourhoods were protective against obesity among higher-SES adolescents, but not among those with a low SES. Additionally, in low- and medium-SES neighbourhoods, obesity prevalence was similar between low- and high-SES adolescents. To our knowledge, this is the first study that has pointed out an interaction effect between the neighbourhood and the individual SES levels on adolescent obesity risk.

Between the school SEC and the student SES, such an interaction effect has not yet been reported. Often, researchers have employed multilevel models to control the environmental SES while investigating student SES and other independent variables without reporting potential interaction effects $[10,14,15,18]$. For example, in the longitudinal study by Niu et al. (2019), a threelevel hierarchical linear model was used to estimate children's BMI growth trajectories within schools [14]. Results showed an inverse relationship between BMI and SES. However, this study did not indicate whether this relationship was specific to a particular school SEC or valid across all schools regardless of their SEC.

This information would be crucial to initiate obesity prevention programs and monitor with greater attention overweight and obesity trends among relevant schools and student subgroups. The lack of a social gradient in low-SEC schools would indicate the need to develop obesity prevention directed toward all adolescents, regardless of their SES. In higher-SEC schools, a social gradient would suggest the need for programs targeted primarily toward adolescents with a lower SES.

Given the role of nutrition and PA, two socially determined factors, on overweight and obesity, there is also a need to control these variables while investigating this relationship $[4,6,19,20]$. Further, analysis of these variables by school SEC and student SES would indicate whether they significantly differ within schools according to student SES, or between schools within the same student-SES category. This information would help to determine whether social differences in overweight and obesity are due, in part, to different lifestyles, or to other environmental aspects.

The main objective of this study was to investigate the interaction effect of school SEC and adolescent SES, while controlling for PA, school lunch and household composition in the prevalence of overweight and obesity among a representative sample of French adolescents of the third most populous département of France. To avoid estimate biases due to BMI disparities between French territories, this study was conducted in a restricted territory (Bouches-du-Rhône, in the South-East of France, the third most populous département) characterized by lower levels of BMI [21], high poverty rates, social inequalities and segregation, and where more than $95 \%$ of the general adolescent population are enrolled in a high school $[22,23]$. These four last territorial specificities are particularly relevant to estimating BMI differences according to school SEC and adolescent SES among a representative sample.

\section{Methods}

\section{Context}

Eighteen public high schools were randomly selected to reflect population geographical and socioeconomic disparities in this area according to the last census report in 2017 [22].

\section{Consent procedures}

We asked the Rector of the Education Authority for administrative approval for inclusion. Eleven high schools in seven towns were finally included and approved in a written consent on March 19, 2019.

The study was also approved by the Aix-Marseille University Ethics Committee (No. 2019-23-05-003).

A parental consent form was distributed to students between March 25 and March 29, 2019, by their Physical Education (PE) teachers. They had 2 weeks to return the form.

\section{Participants}

Of 1257 adolescents, 1149 (91.4\%) returned an accepted parental consent form and were included in the study.

Data collection was conducted from April 3 to May 15,2019 , in classrooms under the supervision of a researcher and a PE teacher.

Questionnaires with more than $50 \%$ of missing responses, aberrant or incoherent answers were excluded. Retained questionnaires with missing responses were 
substituted using multiple imputation with 50 replacement datasets using the $\mathrm{R}$ package mice (v. 3.6.2). The final sample size was 1038. Figure 1 in Additional File 1 details participant selection and exclusion.

\section{Measures}

A specific questionnaire was developed for this study and is available in Additional File 2.

\section{BMI calculation and categorization}

The adolescents self-reported their age, sex, height $(\mathrm{cm})$ and weight $(\mathrm{kg})$. BMI was calculated by dividing weight $(\mathrm{kg})$ by height squared $\left(\mathrm{cm}^{2}\right)$.

Six sets of adolescent outcomes according to age and sex were computed using the 2000 US Centers for Disease Control and Prevention Growth Charts: BMI Zscore, underweight $(\mathrm{BMI}<=5$ th percentile), normal weight (5th percentile $<$ BMI $<85$ th percentile), overweight (85th percentile $<=$ BMI $<95$ th percentile), obesity (BMI $\geq 95$ th percentile) and overweight or obesity (overweight|obesity: BMI $\geq 85$ th percentile) [24].

\section{Household composition Family composition}

The adolescents reported their family composition (whether they lived with both parents, only their father, only their mother, if they switched from time to time or whether they lived without parents). Family composition was divided into two categories (living with both/not living with both parents).

\section{Number of siblings}

The adolescents reported how many siblings they had and if they lived with them at home.

\section{Adolescent SES}

The adolescents reported their father's and mother's occupation according to other French studies $[25,26]$. Father's and mother's occupation were divided into two SES categories (low/high) based on the National Institute of Statistics and Economic Studies (INSEE), which provides average annual income by occupation and territory [22]. Father's and mother's SES were then combined into three categories (low/medium/high) to determine adolescent SES [25]. Adolescents with two low-SES parents were classified as low-SES, those with one low-SES and one high-SES parent as medium-SES and those with two high-SES parents as high-SES. When one of the parents' occupations was missing, adolescent SES was based on the available occupation (father or mother). When both mother's and father's occupation were missing, adolescent SES was NA. All combination and transformed values are available in Additional File 1 Table 1.

Adolescents who did not live with their parents and who did not complete their parents' occupations were excluded from the sample $(n=9,0.8 \%)$.

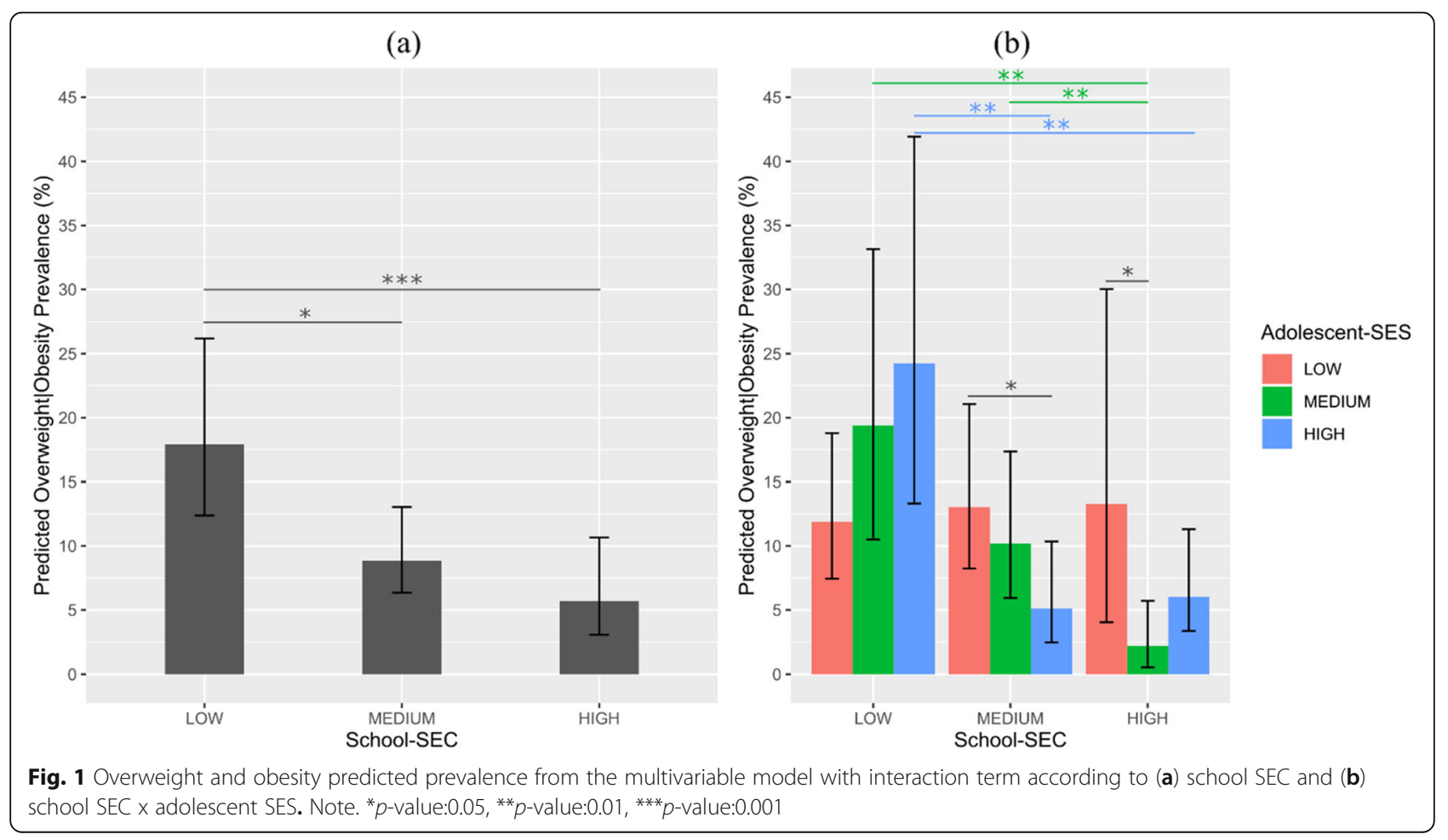




\section{School SEC}

High schools were classified into three SEC groups (low/ medium/high) according to the proportions of low-, medium- and high-SES adolescents they included, and in order to have the most equal sample sizes for low-, medium- and high-SEC subgroups. Each adolescent was placed into one of the three groups according to their high school.

\section{Diet}

\section{School lunch}

To control for diet, the adolescents reported their school meal status. Full board includes lunch and dinner at school. Half board includes lunch at school. No board includes no meal at school. They did not report specifically the numbers of days they ate at school. For readers' information, usually, when an adolescent subscribes to a half-board program, he eats lunch 5 days (Monday to Friday) at school as the half-board payment includes these 5 days. Similarly, full-board pupils have their meals every day at school. Adolescents with no board almost never eat at school as there is no opportunity for day-today lunch payment. Students were divided into two groups (lunch at school/lunch outside school). In France, school lunch respects a strict balanced national norm diet (regardless of their SEC) adapted to adolescents' needs [27]. This is thus a relevant, easily measurable indicator that reflects their lunch type and that can be used by public policies to shape adolescents' diet habits.

\section{PA and its related metabolic equivalent task (MET) Active transportation}

The adolescents reported how many days they used their bicycle for at least $10 \mathrm{~min}$ consecutively and for how many hours per week (transformed into minutes/week). The energy expenditure for bike transportation was defined as 4 MET [28]. The adolescents' active transportation weekly MET was calculated. This question was copied from the Global Physical Activity Questionnaire (https://www.who.int/ncds/surveillance/steps/GPAQ_FR. pdf) [29].

\section{Sport participation}

The adolescents reported how many days and hours they played sport outside of mandatory PE classes per week and indicated their main sport activity. These questions were copied from other sport questionnaires [26, 30]. Sport activity MET was calculated according to the updated compendium of Ainsworth et al. (2011) [31]. Unclassified sports were classified by a committee of four sports scientists and PE teachers according to the closest sport of the compendium in terms of energy expenditure. Individuals' sport participation weekly MET was calculated. All details of MET by sports are available in Additional File 1 Table 2.

Additional questions were asked about their main sport activity (context of participation, years of experience, level of competition and amount of participation) but were not treated in the present study.

\section{PA proxy measure}

A total MET/week was calculated by multiplying active transportation and sport weekly MET. We then divided $\mathrm{MET} /$ week into three categories (low/medium/high) according to three relevant thresholds for long-term cardiovascular diseases risks [32]: low $(<600$ MET $\times$ minutes per week or $<150$ min per week of moderate intensity PA), moderate (600-3000 MET $\times$ minutes per week or $150-750 \mathrm{~min}$ per week) and high PA (>3000 MET $\times$ minutes per week or $>750$ min per week).

\section{Analysis}

All statistical analyses were performed using $\mathrm{R}$ version 3.6.2.

First, sample description was performed for the whole sample and by school SEC.

Second, school lunch and PA level relationship with adolescent SES and school SEC was analysed. Crosstables with chi-square statistics and multivariable logistic regression were used to determine whether they were significantly linked. The significance level was set at 0.05 .

Third, overweight and obesity risk was analysed in univariable and multivariable logistic regression analyses with and without interaction term between adolescent SES and school SEC. An additional model using the forward and backward stepwise technique was performed. The goal was to create the simplest regression model that best fitted the study data. Model fit was compared using the Akaike Information Criterion (AIC), the Area Under Curve (AUC), and the specificity and sensitivity results. The best model was chosen according to these latter parameters assuming that (i) the lower the AIC, the better the model, (ii) the higher the AUC the better the model, (iii) and the higher the specificity and sensitivity, the better the model. For each model, the bootstrap method was used to account for generalizability error, and bias-corrected 95\% confidence intervals were calculated based on 3000 resamples of the data (minimum recommended resamples: 1000) [33].

Fourth, the best model overweight and obesity predicted prevalence output was plotted either (i) separately by adolescent SES and school SEC if the interaction model fit the data less well or (ii) according to adolescent SES and school SEC if the interaction model fit the data better. Predicted prevalences were calculated using a marginal probability prediction with the package 
emmeans (v. 1.5.3). We also presented observed number and prevalence of overweight|obesity by school SEC and adolescent SES.

Finally, contrast analyses were performed using oddsratio to compare overweight and obesity risk by variable category. Contrast analyses aimed to compare this risk within school SEC according to adolescent SES and between school SEC for each adolescent-SES category. These analyses help in determining whether a social gradient exists within all school SECs or is valid for only one or two specific school SECs. It also helps to determine whether school SEC is positively associated with a lower overweight and obesity risk among all adolescentSES categories, in only one or two specific SES categories, or is not associated.

\section{Results}

Table 1 provides overall sample descriptive statistics. Results showed a BMI Z-score below the international mean (Mean $=-0.09 \pm 1.01$ ). The sample comprised $6.3 \%$ underweight, $81.5 \%$ normal weight, $8.9 \%$ overweight and $3.4 \%$ obese adolescents. Overweight|obesity prevalence in this area was below national prevalence among adolescents aged $13-15$ (18.0\% vs. $12.2 \%)$.

\section{School lunch and physical activity levels by school SEC}

Adolescents enrolled in medium- and high-SEC schools were more likely to eat at school compared with those enrolled in low-SEC schools $\left(\mathrm{OR}_{\text {medium } / \mathrm{low}}=3.77,95 \%\right.$ $\mathrm{CI}=2.44-5.90$ and $\mathrm{OR}_{\text {high } / \text { low }}=17.23,95 \% \mathrm{CI}=10.66-$ 28.43 , respectively). Detailed analysis of school differences in lunch type are provided in Additional File $1 \mathrm{Ta}-$ bles 3 (cross-tables and chi-square statistics), 4 (multivariable logistic regression analyses) and 5 (interaction term contrast analysis).

Adolescents in medium- and high-SEC schools were more likely to have medium or high PA levels rather than low PA levels compared with those enrolled in lowSEC schools $\left(\mathrm{OR}_{\text {medium } / \text { low }}=2.93,95 \% \mathrm{CI}=1.93-4.50\right.$ and $\mathrm{OR}_{\text {high/low }}=2.63,95 \% \mathrm{CI}=1.61-4.32$, respectively). Detailed analyses of school differences in PA levels are provided in Additional File 1 Tables 6 (cross-tables and chi-square statistics), 7 (cross-tables and chi-square statistics), 8 (multivariable logistic regression analyses) and 9 (interaction term contrast analysis).

Those who ate their lunch at school were not more likely to have higher levels of PA than those who ate their lunch outside school $(\mathrm{OR}=0.77,95 \% \mathrm{CI}=0.53$ 1.12).

\section{Overweight|obesity risk}

Table 2 shows results of univariable and multivariable models without or with interaction term between adolescent SES and school SEC.

\section{Models comparison}

Comparison of the multivariable models without and with interaction terms showed a significant interaction effect between adolescent SES and school SEC. The interaction model fits the data better compared with the multivariable model without interaction term (AIC = 718.5 and $\mathrm{AUC}=0.691$ with a sensitivity of $79.3 \%$ and a specificity of $50.1 \%$ versus $\mathrm{AIC}=729$ and $\mathrm{AUC}=0.653$ with a sensitivity of $73.6 \%$ and a specificity of $50.9 \%$ ). Hence, results from the multivariable model with interaction are presented below.

\section{Main effects}

We observed an effect of age, sex, and PA level in overweight|obesity risk. Older adolescents and girls were less likely to be overweight|obese compared with younger adolescents and boys $(\mathrm{OR}=0.81,95 \% \mathrm{BCa} \mathrm{CI}=0.70$ 0.97 and $\mathrm{OR}=0.65,95 \% \mathrm{BCa} \mathrm{CI}=0.43-0.99$, respectively). Similarly to univariable analysis, adolescents with a high PA level were less likely to be overweight|obese compared with those with a low PA level $(\mathrm{OR}=0.42$, $95 \% \mathrm{BCa} \mathrm{CI}=0.18-0.95)$.

\section{Interaction effects analysis}

Table 3 shows contrast analysis results from the multivariable model with interaction term within school SEC and by adolescent SES and between school SECs according to adolescent SES. Results are expressed as oddsratio.

Within school SEC, a statistically significant social gradient was observed in medium- and high-SEC schools while no statistically significant difference was observed in low-SEC schools. In medium-SEC schools, low-SES adolescents were more likely to be overweight|obese compared with high-SES adolescents $(\mathrm{OR}=2.79,95 \%$ $\mathrm{BCa} \mathrm{CI}=1.22-7.41)$. In high-SES schools, low-SES adolescents were at greater risk compared with mediumSES adolescents $(\mathrm{OR}=6.86, \quad 95 \% \quad \mathrm{BCa} \quad \mathrm{CI}=1.06-$ $\left.5.22^{*} 10^{6}\right)$. In low-SEC schools, no statistically significant difference was observed but the predicted and observed prevalence (Table 4) appeared to be higher among high(23.4\%) and medium- (18.6\%) compared with low-SES (11.4\%) adolescents.

Within adolescent SES, an absence of school-SEC effect in overweight|obesity risk for low-SES adolescents was observed. By contrast, medium-SES adolescents were at greater risk in low- and medium- compared with high-SEC schools $\left(\mathrm{OR}_{\text {low } / \text { high }}=10.75,95 \% \mathrm{BCa} \mathrm{CI}=\right.$ 2.67-64.57 and $\mathrm{OR}_{\text {medium } / \text { high }}=5.08,95 \% \mathrm{BCa} \quad \mathrm{CI}=$ 1.55-24.84, respectively). High-SES adolescents were at greater risk in low- compared with medium- and highSEC schools $\left(\mathrm{OR}_{\text {low } / \text { medium }}=5.94,95 \% \mathrm{BCa} \mathrm{CI}=1.94\right.$ 17.29 and $\left.\mathrm{OR}_{\text {low } / \text { high }}=4.99,95 \% \mathrm{BCaCI}=1.71-13.14\right)$. 
Table 1 Descriptive Statistics across the whole sample and by school SEC

\begin{tabular}{|c|c|c|c|c|}
\hline \multirow[t]{2}{*}{ Variables } & \multirow[t]{2}{*}{ All } & \multicolumn{3}{|c|}{ School SEC } \\
\hline & & Low $(n=3)$ & Medium $(n=5)$ & High $(n=3)$ \\
\hline Age $(M, S D)$ & $15.92(1.33)$ & $16.61(1.16)$ & $15.37(1.24)$ & $15.82(1.26)$ \\
\hline \multicolumn{5}{|l|}{$\operatorname{Sex}(n, \%)$} \\
\hline Boys & $515(49.6 \%)$ & $186(53.6 \%)$ & $195(51.6 \%)$ & $142(45.4 \%)$ \\
\hline Girls & $523(50.4 \%)$ & $161(46.4 \%)$ & $183(48.4 \%)$ & $171(54.6 \%)$ \\
\hline \multicolumn{5}{|l|}{ Body Mass Index } \\
\hline Weight / Height (M, SD) & $20.83(3.32)$ & $21.97(3.8)$ & 20.59 (3.09) & $19.85(2.57)$ \\
\hline CDC Z-Scores (M, SD) & $-0.09(1.01)$ & $0.11(1.05)$ & $-0.04(0.97)$ & $-0.37(0.94)$ \\
\hline Underweight & $65(6.3 \%)$ & $16(4.6 \%)$ & $22(5.8 \%)$ & $27(8.6 \%)$ \\
\hline Normal Weight & $846(81.5 \%)$ & $274(79.0 \%)$ & $308(81.5 \%)$ & $264(84.3 \%)$ \\
\hline Overweight & $92(8.9 \%)$ & $38(11.0 \%)$ & $36(9.5 \%)$ & $18(5.8 \%)$ \\
\hline Obesity & $35(3.4 \%)$ & $19(5.5 \%)$ & $12(3.2 \%)$ & $4(1.3 \%)$ \\
\hline Overweight|Obesity & $127(12.2 \%)$ & $57(16.4 \%)$ & $48(12.7 \%)$ & $22(7.0 \%)$ \\
\hline \multicolumn{5}{|l|}{ Physical Activity } \\
\hline Low & $282(27.2 \%)$ & $142(40.9 \%)$ & 79 (20.9\%) & $61(19.5 \%)$ \\
\hline Medium & $623(60.0 \%)$ & $162(46.7 \%)$ & $245(64.8 \%)$ & $216(69.0 \%)$ \\
\hline High & $133(12.8 \%)$ & $43(12.4 \%)$ & $54(14.3 \%)$ & $36(11.5 \%)$ \\
\hline \multicolumn{5}{|l|}{ Adolescent SES } \\
\hline Low & $351(33.8 \%)$ & $214(61.7 \%)$ & $108(28.6 \%)$ & $29(9.3 \%)$ \\
\hline Medium & $277(26.7 \%)$ & $63(18.2 \%)$ & $118(31.2 \%)$ & $96(30.7 \%)$ \\
\hline High & $368(35.5 \%)$ & $50(14.4 \%)$ & $137(36.2 \%)$ & $181(57.8 \%)$ \\
\hline NA & $42(4.1 \%)$ & $20(5.8 \%)$ & $15(4.0 \%)$ & $7(2.2 \%)$ \\
\hline \multicolumn{5}{|l|}{ School Lunch (n, \%) } \\
\hline Lunch outside school & $490(47.2 \%)$ & $304(87.6 \%)$ & $189(50.0 \%)$ & $55(17.6 \%)$ \\
\hline Lunch at school & $548(52.8 \%)$ & $43(12.4 \%)$ & $189(50.0 \%)$ & $258(82.4 \%)$ \\
\hline \multicolumn{5}{|l|}{ Household Composition } \\
\hline Live with both parents & $680(65.5 \%)$ & $218(62.8 \%)$ & $231(61.1 \%)$ & $231(73.8 \%)$ \\
\hline Do not live with both parents & $358(34.5 \%)$ & $129(37.2 \%)$ & 147 (38.9\%) & $82(26.2 \%)$ \\
\hline Number of Siblings (M, SD) & $2.13(1.55)$ & $2.9(1.76)$ & $1.92(1.45)$ & $1.54(0.98)$ \\
\hline Overall & $1038(100.0 \%)$ & 347 (100.0\%) & $378(100.0 \%)$ & $313(100.0 \%)$ \\
\hline
\end{tabular}

Figure 1 shows the predicted prevalence from the multivariable model with interaction term with acceleratedbootstrap confidence interval for (a) main effects of school SEC and (b) interaction effects between adolescent SES and school SEC.

All other statistically significant differences (between adolescent SES and school SEC) are available in Additional File 1 Table 10. All statistically significant differences indicated an increased risk for adolescents with a lower SES and in lower-SEC schools.

\section{Discussion}

The main objective of this study was to investigate the interaction effect of school SEC and adolescent SES in the prevalence of overweight and obesity among a representative sample of French adolescents of the third most populous département of France.

\section{Consistency of results with previous findings}

In France, multiple studies have shown that overweight and obesity prevalence among the general population (children, adolescents and adults) varied according to the territory (département) 21. It is acknowledged that overweight and obesity prevalence is lower in the SouthEast of France - which is the area concerned by our study - compared with the national level.

Among adolescents, to our knowledge, no study has documented systematic territorial inequalities in overweight and obesity prevalence. A recent national study (2019) conducted among adolescents aged 13-15 showed an overweight|obesity prevalence of $18 \%$, and an 
Table 2 Results from the univariable, full model and stepwise procedure with bias-corrected and accelerated-bootstrap confidence interval (BCa) in overweight|obesity

\begin{tabular}{|c|c|c|c|c|}
\hline Variables & $\begin{array}{l}\text { Univariable } \\
\text { Analysis }\end{array}$ & $\begin{array}{l}\text { Full Model without interaction } \\
\text { with } \mathrm{BCa}\end{array}$ & $\begin{array}{l}\text { Full Model with interaction } \\
\text { and } \mathrm{BCa}\end{array}$ & $\begin{array}{l}\text { Stepwise Model } \\
\text { with BCa }\end{array}$ \\
\hline Age & $0.89[0.77 ; 1.02]$ & $0.80^{* *}[0.68 ; 0.95]$ & $0.81^{*}[0.70 ; 0.97]$ & $0.81 *[0.69 ; 0.98]$ \\
\hline \multicolumn{5}{|l|}{ Sex } \\
\hline \multicolumn{5}{|l|}{ Girls (ref.) } \\
\hline Boys & $1.29[0.89 ; 1.87]$ & $1.53^{*}[1.03 ; 2.29]$ & $1.54^{*}[1.01 ; 2.34]$ & $1.53[1.00 ; 2.35]$ \\
\hline \multicolumn{5}{|l|}{ Adolescent SES } \\
\hline \multicolumn{5}{|l|}{ Low (ref.) } \\
\hline Medium & $0.76[0.47 ; 1.21]$ & $0.97[0.58 ; 1.62]$ & $1.78[0.83 ; 3.91]$ & $1.78[0.71 ; 3.51]$ \\
\hline High & $0.59^{*}[0.37 ; 0.93]$ & $0.94[0.55 ; 1.59]$ & $2.37[1.00 ; 5.52]$ & $2.38[0.99 ; 5.54]$ \\
\hline \multicolumn{5}{|l|}{ School SEC } \\
\hline \multicolumn{5}{|l|}{ Low (ref.) } \\
\hline Medium & $0.74[0.49 ; 1.12]$ & $0.58[0.33 ; 1.01]$ & $1.11[0.54 ; 2.32]$ & $1.15[0.56 ; 2.28]$ \\
\hline High & $\begin{array}{l}0.38^{* * *}[0.22 ; \\
0.64]\end{array}$ & $0.34^{* *}[0.17 ; 0.68]$ & $1.14[0.31 ; 3.52]$ & $1.24[0.27 ; 3.29]$ \\
\hline \multicolumn{5}{|l|}{ School Lunch } \\
\hline \multicolumn{5}{|l|}{ Outside of school (ref.) } \\
\hline At school & $0.70[0.47 ; 1.01]$ & $1.08[0.66 ; 1.76]$ & $1.16[0.69 ; 1.91]$ & - \\
\hline \multicolumn{5}{|l|}{ Physical Activity } \\
\hline \multicolumn{5}{|l|}{ Low PA (ref.) } \\
\hline Medium PA & $0.82[0.55 ; 1.24]$ & $1.01[0.65 ; 1.6]$ & $1.03[0.65 ; 1.65]$ & $1.02[0.64 ; 1.65]$ \\
\hline High PA & $0.48^{*}[0.22 ; 0.95]$ & $0.44^{*}[0.19 ; 0.93]$ & $0.42^{*}[0.18 ; 0.95]$ & $0.41^{*}[0.17 ; 0.90]$ \\
\hline \multicolumn{5}{|l|}{ Household Composition } \\
\hline \multicolumn{5}{|l|}{ Live with both parents (ref.) } \\
\hline Do not live with both parents & $1.13[0.77 ; 1.66]$ & $1.01[0.66 ; 1.52]$ & $1.01[0.65 ; 1.58]$ & - \\
\hline Number of Siblings (M, SD) & $1.14^{*}[1.02 ; 1.27]$ & $1.10[0.97 ; 1.25]$ & $1.12[0.98 ; 1.28]$ & $1.11[0.97 ; 1.26]$ \\
\hline \multicolumn{5}{|l|}{ Adolescent SES x School SEC } \\
\hline $\begin{array}{l}\text { Low Adolescent SES x Low School } \\
\text { SEC }\end{array}$ & & & ref. & ref. \\
\hline $\begin{array}{l}\text { Medium Adolescent SES x Medium } \\
\text { School SEC }\end{array}$ & & & $0.43[0.15 ; 1.30]$ & $0.43[0.15 ; 1.36]$ \\
\hline $\begin{array}{l}\text { High Adolescent SES x Medium } \\
\text { School SEC }\end{array}$ & & & $0.15^{* *}[0.05 ; 0.56]$ & $0.16^{* *}[0.04 ; 0.50]$ \\
\hline $\begin{array}{l}\text { Medium Adolescent SES x High- } \\
\text { School SEC }\end{array}$ & & & $0.08^{*}[0.00 ; 0.62]$ & $0.08^{*}[0.00 ; 0.70]$ \\
\hline $\begin{array}{l}\text { High Adolescent SES x High-School } \\
\text { SEC }\end{array}$ & & & $0.18^{*}[0.04 ; 0.89]$ & $0.18^{*}[0.04 ; 0.82]$ \\
\hline Aikake Information Criterion & & 729 & 718.52 & 714.9 \\
\hline Sensitivity & & $73.6 \%$ & $79.3 \%$ & $79.3 \%$ \\
\hline Specificity & & $50.9 \%$ & $50.1 \%$ & $50.9 \%$ \\
\hline Area Under Curve & & 0.653 & 0.691 & 0.690 \\
\hline
\end{tabular}

Note. Outcome variable: overweight or obesity; Ref.: Reference category; ${ }^{*} p$-value:0.05, ${ }^{* *} p$-value:0.01, ${ }^{* * *} p$-value:0.001

obesity prevalence of $5.2 \%$ [25]. In the present study, an overweight|obesity prevalence of $12.2 \%$ and an obesity prevalence of $3.4 \%$ were observed among adolescent students aged 13-19 from South-East France, which is consistent with overweight and obesity territory disparities observed among the general French population.

The previous national study also observed that lowerSES adolescents - measured by their parents' 
Table 3 Odds-Ratio Contrast Analysis of School SEC and Adolescent SES with bias-corrected and accelerated-bootstrap confidence intervals

\begin{tabular}{lll}
\hline Within School & Adolescent-SES Contrasts & Odds-Ratio \\
Low-SEC & Low-Medium & $0.56[0.26 ; 1.21]$ \\
& Medium-High & $0.75[0.27 ; 1.92]$ \\
Medium-SEC & Low-High & $0.42[0.19 ; 1.04]$ \\
& Low-Medium & $1.32[0.63 ; 2.84]$ \\
& Medium-High & $2.11[0.85 ; 5.29]$ \\
High-SEC & Low-High & $2.79^{*}[1.22 ; 7.41]$ \\
& Low-Medium & $6.86^{*}\left[1.06 ; 5.22^{*} 10^{6}\right]$ \\
Within SES & Medium-High & $0.35[0.00 ; 1.63]$ \\
Low SES & Low-High & $2.39[0.55 ; 7.85]$ \\
& School SEC Contrasts & Odds-Ratio \\
& Low-Medium & $0.90[0.44 ; 1.79]$ \\
& Medium-High & $0.98[0.33 ; 3.99]$ \\
Medium SES & Low-High & $0.88[0.29 ; 3.55]$ \\
& Low-Medium & $2.12[0.80 ; 5.47]$ \\
& Medium-High & $5.08^{* *}[1.55 ; 24.84]$ \\
& Low-High & $10.75^{* *}[2.67 ; 64.57]$ \\
High SES & Low-Medium & $5.94^{* *}[1.94 ; 17.29]$ \\
& Medium-High & $0.84[0.32 ; 2.20]$ \\
& Low-High & $4.99^{* *}[1.71 ; 13.14]$ \\
\hline
\end{tabular}

Note. ${ }^{*} p$-value:0.05, ${ }^{* *} p$-value:0.01, ${ }^{* * *} p$-value:0.001

occupations - were less likely to eat their lunch at school [25]. This result was also observed in the present study, but it was mainly explained by the school SEC instead of the adolescent SES. In each school SEC, the proportions of adolescents having their lunch at school was not different according to their SES. Meanwhile, school SEC was strongly linked to having lunch at school, ranging from $12.4 \%$ in low-SEC schools, to 50.0 and $82.4 \%$ in medium- and high-SEC schools respectively (Additional File 1, Tables 3-5).

Consistent with previous findings, an effect of PA was also observed in multivariable models, meaning that a high level of PA is negatively linked to overweight and obesity, regardless of adolescent SES or school SEC [13, 19]. Moreover, statistically significant social differences were also observed in overweight and obesity, as pointed out by previous national reports and international studies $[10,14,15,25]$.

\section{Novel findings of the study}

The originality of this study was to investigate and analyse a potential interaction effect between school SEC and adolescent SES, which has not been documented before. Results from the multivariable model including lunch type, PA, sex, age and household composition, showed a statistically significant interaction effect between school SEC and adolescent SES.

The model with interaction effect fits the data better compared with the model without interaction.

We observed that low-SES adolescents had a similarly high overweight|obesity prevalence in all school SECs. By contrast, medium- and high-SES adolescents were at greater risk in low-SEC schools compared with higherSEC schools. In addition, in low-SEC schools, no statistically significant difference across adolescent SES was observed but overweight|obesity prevalence appeared to be much higher among medium- and high-SES adolescents, while in medium-SEC and high-SEC schools, adolescent SES was statistically significantly negatively associated with overweight|obesity risk.

One might have supposed, in view of the strong correlation between lunch type and PA with school SEC and adolescent SES (see Additional File 1, Tables 3 to 8), that social differences in overweight and obesity could have been mainly due to these different life habits. However, observing these social differences after having adjusted the models for these confounders underlines the potential role of other factor(s) responsible for these differences.

In this study, the lunch type of the adolescents was controlled because in each school SEC the lunch respects a recommended national norm of balanced diet adapted to adolescents' needs [27]. Our results could suggest then that what adolescents eat outside lunch might have a greater influence to explain their weight status and the subsequent social differences.

In low-SEC schools, an inversed social gradient was observed, with the highest overweight|obesity prevalence in this study ranging from $11.4 \%$ for low-SES adolescents to $18.6 \%$ for medium-SES and $23.4 \%$ for high-SES

Table 4 Observed and predicted number and prevalence of overweight and obesity by adolescent-SES and school-SEC

\begin{tabular}{|c|c|c|c|c|c|c|c|}
\hline \multirow[t]{3}{*}{ Variables } & & \multicolumn{6}{|l|}{ School SEC } \\
\hline & & \multicolumn{2}{|l|}{ Low } & \multicolumn{2}{|l|}{ Medium } & \multicolumn{2}{|l|}{ High } \\
\hline & & Observed & Predicted & Observed & Predicted & Observed & Predicted \\
\hline \multirow[t]{3}{*}{ Adolescent SES } & Low & $29(13.6 \%)$ & $24(11.4 \%)$ & 19 (17.6\%) & 14 (12.9\%) & $5(17.2 \%)$ & $4(13.7 \%)$ \\
\hline & Medium & 13 (20.6\%) & $12(18.6 \%)$ & 17 (14.4\%) & $12(10.2 \%)$ & $3(3.1 \%)$ & $2(2.3 \%)$ \\
\hline & High & 12 (24.0\%) & $12(23.4 \%)$ & $9(6.6 \%)$ & $7(5.2 \%)$ & 14 (7.7\%) & $11(6.3 \%)$ \\
\hline
\end{tabular}


adolescents. In these schools, adolescents were less prone to eat at school, regardless of their SES.

Notably, a previous study has shown that lunch outside school is influenced by the surrounding restaurant offers [27]. It has been shown that fast-food restaurant proximity to schools is positively linked to adolescent BMI $[7,8]$. Further, low-SEC school neighbourhoods are characterized by a higher density of fast-food restaurants $[34,35]$. It is reasonable to think that adolescents from these schools mainly eat their lunch in fast-food restaurants, which could be an explanation of the high prevalences observed.

At the same time, previous studies have generally argued that the dietary habits of low-SES families were constituted by poor nutrients and increased snacking time to a greater extent than for higher-SES adolescents, both factors associated with an increase in BMI [11, 12, $34,35]$. However, the specific result of the present study in low-SEC schools could suggests that medium- and high-SES adolescents enrolled in these schools might also be particularly concerned by a bad diet outside of the lunch at school, which goes against traditional assumptions regarding the general higher-SES adolescent population.

These results should foster the development of studies to understand more clearly this phenomenon of social gradient inversion that, to our knowledge, has never been documented before. More generally, it should foster public policies to develop prevention programs toward all adolescents in low-SEC schools.

In medium- and high-SEC schools, the results show the presence of a more "conventional" social gradient where higher-SES adolescents were less at risk compared with low-SES adolescents $[10,14,15]$. In view of the existing literature, this result could be understood as reflecting both (i) the role of the surrounding restaurants offers that are of better quality [34, 35] and are less frequented by adolescents due to the large proportions who eat at school $(82.4 \%$ ), and (ii) the better dietary habits of higher-SES adolescents outside schools compared with low-SES adolescents. These interpretations are in line with most previous findings in the field.

In summary, these results show that the frequentation of higher-SEC school environments does not benefit all adolescents equally, depending on their SES. On the other hand, the unfavourable environment of low-SEC schools substantially affects all adolescents, regardless of their SES. This result has already been observed in academic performance, but has never previously been shown in overweight and obesity social studies [36, 37].

Further studies might try to understand how adolescents' life habits are shaped in different school SECs. This could help to better understand the reality of under-represented groups in specific social contexts.
The results might help to understand why (i) high-SES adolescents presented high overweight and obesity prevalence in low-SEC schools and (ii) low-SES adolescents still presented high overweight and obesity prevalence in medium- and high-SEC schools.

\section{Limitations \\ Self-reported measures \\ Anthropometric measurements}

Due to the very low number of medical doctors (MD) in schools in France (only 1000 MD for 12,000,000 students), and their overwork (only $57 \%$ of students had a health check in 2015), we chose to ask the adolescents to self-report their age, sex, height and weight [38]. However, this implies potential bias considering that some studies have shown discrepancies between selfreported and physical measures of height and weight. Principally, self-reported weight is underestimated by overweight and obese adolescents [39-41]. This led to an underestimation of overweight and obesity prevalence in self-report studies of overweight and obesity. In the present study, social differences in overweight and obesity might have been underestimated. In addition, studies showed that BMI accuracy based on self-report differed significantly between male and female, but not enough to entail incorrect weight status classification [41-43]. Finally, temporal changes in bias of BMI scores based on self-reported height and weight have declined, leading to more accurate BMI categorizations between 1988 and 2008. This has been explained by the changing social norms regarding overweight and obesity due to their increasing prevalence and acceptability among the population [44]. It suggests then that, in the present study, selfreported bias might be even more reduced given the rising trends of overweight and obesity. All these studies gave confidence regarding the results from this study based on self-reported height and weight for adolescent weight status classification. However, to our knowledge, no study has reported bias differences between SES. It would be interesting, in a further study, to perform sensitivity analysis to measure bias accurately in selfreported height and weight by sex and SES, ideally in a sample of French adolescents.

\section{Physical activity}

In this study, the adolescents self-reported their PA, including cycling and sports. Questions related to cycling were copied from the GPAQ questionnaire, which show moderate to good test-retest reliability in adult samples $[45,46]$. A previous French study also showed that the GPAQ underestimated total PA compared with the accelerometer [45]. This discrepancy has been specified by a study by Cleland et al. (2014) which showed that highly active adults tended to over-report their total PA, 
while inactive adults tended to under-report their total sedentary time [47]. Another study showed that females tended to better report total moderate-to-vigorous PA (MVPA) compared to males [48]. Cleland et al. also found that BMI was not a predictor of discordance for total MVPA, while adults with higher level of education tended to report more precisely their total MVPA compared with those with lower level of education. More precisely, adults with lower level of education tended to over-report their total MVPA.

If all the above-mentioned discrepancies are similar between adults and adolescents - which has not been tested previously - it would imply that in the present study social differences in PA might have been underestimated, meaning that lower SES adolescents might have lower total PA than mentioned. Thus, the objective PA gap between high-SES and low-SES adolescents might be higher than measured in the present study. However, these interpretations might be tempered as, in the present study, we observed that school SEC was more linked to total PA than adolescent SES. However, previous studies that compare self-report measures of total PA with accelerometer did not control for the SEC of the living environment of participants. In addition, to our knowledge, no study has explicitly tested these discrepancies in a sample of adolescents.

Finally, concerning sport participation, specific question were added that were not included in the GPAQ. The adolescents were explicitly asked to report whether they played sport every week, the volume of sport participation, and the main sport activity practiced each week. In the current form of the GPAQ, questions related to sport are based on the perceived intensity of performed sports activity (low, medium and high) without asking explicitly what sports adolescents play. Consequently, the total estimated MET per week are computed by multiplying 3 (low intensity), 6 (moderate intensity) or 8 (high intensity) by the total volume of participation in low, moderate or vigorous PA. However, sports are various in their form and intensity, which has been measured with the total oxygen cost of each sport in laboratory or field experiments [31]. To overcome this bias, we asked the adolescents to report the sport they practice the most each week and then compute adolescent sport total/MET according to the Compendium of Ainsworth et al. [31] In our opinion, this provides potentially better reliability of sport total/MET computed from these questions in comparison with the sport questions used in the GPAQ. Fortunately, consistently with previous studies, it was observed that PA was negatively associated with overweight and obesity risk, which adds confidence regarding the reliability of questions used for public health assessment. Nevertheless, a further study should specifically compare self-reported PA (including specific questions about sports) to direct measurements on a sample of French adolescents. It would help to establish whether the results observed concerning PA were under- or over-estimated, and whether subgroups' characteristics are predictors of self-reported PA discordance compared with direct measurements (e. g. accelerometer).

\section{Sample size}

Finally, French high schools are characterized by strong social segregation [23]. The present study highlights this phenomenon, where high-SEC schools had low numbers of low-SES adolescents, and low-SEC schools had low numbers of high-SES adolescents. This observed disparity clearly lowered the power of the test when comparing small adolescent subgroups with bigger ones, which is observed in large confidence intervals (for example lowSES compared with high-SES adolescents in high-SEC schools). One could suggest the development of mixed methods to better understand the reality of underrepresented groups in specific school SECs. Qualitative studies would help to understand why high-SES adolescents presented high overweight and obesity prevalence in low-SEC schools. Similarly, this could also be undertaken in high-SEC schools for low-SES adolescents. Measuring these crossed perceptions could help to understand adolescent development in different social settings, while having parent(s) stemming from the same social class.

\section{Conclusion}

This is the first study that has examines the interaction effect between school SEC and adolescent SES in overweight and obesity risk among a representative sample of adolescents of the third most populous département of France. The results showed a significant interaction effect, presenting (i) low-SES adolescents, regardless of their high-school SEC, and (ii) low-SEC high schools, regardless of adolescent SES, as high priority targets for obesity prevention initiatives. In addition, a social gradient inversion has been observed in low-SEC schools where higher-SEC adolescents had higher prevalence of overweight and obesity compared with low-SES adolescents. These results may foster the development of obesity prevention initiatives directed toward specific schools and adolescent social subgroups, for example through incentives to have lunch at school and/or nutrition and PA educational programs.

\section{Abbreviations}

AIC: Akaike Information Criterion; AUC: Area Under Curve; BMI: Body Mass Index; MET: Metabolic Equivalent of Task; INSEE: National Institute of Statistics and Economic Studies; OR: Odds-Ratio; Overweight/obesity: Overweight or obesity; PA: Physical Activity; PE: Physical Education; SEC: Socioeconomic Composition; SES: Socioeconomic Status; 95\%BCa Cl: 95\% acceleratedbootstrap confidence interval 


\section{Supplementary Information}

The online version contains supplementary material available at https://doi. org/10.1186/s12889-021-11752-2

Additional file 1 Supplementary Fig. 1. Study Participants Selection and Filtering for Analysis. Supplementary Table 1. Father and Mother Occupations Combined and Translated to Three Adolescent-SES levels. Supplementary Table 2. List of sports activities (name, number, proportion) declared by adolescents and their related metabolic equivalent and mean of computed MET/min/week. Supplementary Table 3. School Lunch by School SEC and Adolescent SES. Supplementary Table 4. Results from the full model without and with interaction in School Lunch. Supplementary Table 5. School Lunch Odds-Ratio Contrast Analysis of School SEC and Adolescent SES. Supplementary Table 6. PA Level by School SEC and Adolescent SES. Supplementary Table 7. PA Level by School SEC and Adolescent SES. Supplementary Table 8. Results from the full model without and with interaction in Medium|High PA Level. Supplementary Table 9. PA Level Odds-Ratio Contrast Analysis of School-SEC and Adolescent SES. Supplementary Table 10. All significant crossed interaction effects. Supplementary Table 11. Results from the univariable, full model without and with interaction to estimate BMI Z-Scores.

Additional file 2 Questionnaire. Adolescent students' physical and sport activity.

\section{Acknowledgements}

The authors wish to thank the Rector of the Education Authority, the AixMarseille University Ethics Committee, the heads of high schools, the Physical Education teachers and all students and parents who agreed to participate in this study.

The authors wish to thank all Administrative and Support Staff who helped in data collection and typing.

\section{Authors' information (optional)}

ML completed a PhD in Sport and Physical Activity Epidemiology in 2018 at the Aix-Marseille University, France. The PhD was focused on the monitoring of sport participation rates and their associated injury risk over 15 years among representative samples of high-school students. He earned the AixMarseille University Thesis Prize in 2019. After a postdoctoral study on the social determinants of Paralympic athletes' performance and health at the French Institute of Sport, he is now an associate professor in physical and sport education at the Aix-Marseille University.

OR was formerly engaged in physical education and training in sports activities. He is now a PhD and associate professor in the Institut National du Professorat et de l'Education of the University of Aix-Marseille and researcher in the Institute of Science of Movement, Marseille. He is specialized in physical activity and health for public health observations and for clinical applications. Based on experimental studies, he focuses especially on the physiological and psychological repercussions of physical activity programs on obese adolescent girls and boys. Moreover he studies running field tests adapted for obese people with interval and continuous designs.

MT studies the physical and sports activity of young people. Based on qualitative surveys, he focuses on the process of joining or quitting sport. His quantitative work is part of an epidemiological perspective aimed at identifying, based on sociodemographic factors, exposure to the risk of injury, variations in the rate of practice and changes in sporting preferences. All of the information gathered is intended to help public authorities whether through sports promotion campaigns or direct intervention with adolescents (clubs, schools) - to target their actions. Within the Institut National du Professorat et de l'Education of the University of Aix-Marseille, he is responsible for training physical education and sports teachers. JG is full professor at the Institute of Movement Sciences, Aix-Marseille University. His main topics are: $1 /$ emergence of adventure sports in contemporary societies; $2 /$ reasons for the current practice and drop-out of leisure sports activities among adolescents; 3 / motives and contexts of risk-taking behaviours in sports; 4/ objective measurement of factors of injuries, overweight and consumption of alcohol and doping substances.

\section{Authors' contributions}

JG asked for authorization from the Rector of the Education Authority. ML was responsible for the ethical committee procedure. ML, MT and JG conceptualized the study design including sampling design and questionnaire construction. ML, OR, MT and JG conceptualized the analysis plan and reviewed the final manuscript. ML computed overweight and obesity cut-off according to the Center for Disease Control. OR computed sport metabolic equivalent of task according to the Compendium of Ainsworth et al. (2011). ML did analysis, wrote methods and results, and computed tables, figures, and additional file. ML, OR, MT and JG wrote the introduction and discussion. ML, OR, MT and JG reviewed the introduction, methods, results, discussion, tables, figures and additional file. All authors read and approved the final manuscript.

\section{Funding}

This research did not receive any specific grant from funding agencies in the public, commercial, or not-for-profit sectors.

\section{Availability of data and materials}

The datasets used and/or analysed during the current study are available from the corresponding author on reasonable request.

\section{Declarations}

Ethics approval and consent to participate

The study was approved by the Rector of the Education Authority on March 19th 2019.

The study was approved by the Aix-Marseille University Ethics Committee (No. 2019-23-05-003).

A parental consent form was distributed to students between March 25 and March 292019 by their Physical Education teachers. They had two weeks to return the form. Of 1257 adolescents, 1149 (91.4\%) returned a completed parental consent form and were included in the study.

\section{Consent for publication}

Not applicable.

\section{Competing interests}

The authors declare that they have no competing interests.

\section{Author details}

${ }^{1}$ Aix Marseille Univ, ADEF, Marseille, France. ${ }^{2}$ Structure Fédérative d'Études et de Recherches en Éducation de Provence, FED 4238, Marseille, France. ${ }^{3}$ Aix Marseille Univ, CNRS, ISM, UMR 7287, Marseille, France.

Received: 7 December 2020 Accepted: 8 September 2021

Published online: 11 October 2021

\section{References}

1. Whitaker RC, Wright JA, Pepe MS, Seidel KD, Dietz WH. Predicting obesity in young adulthood from childhood and parental obesity. N Engl J Med. 1997; 337(13):869-73. https://doi.org/10.1056/NEJM199709253371301.

2. Magarey AM, Daniels LA, Boulton TJ, Cockington RA. Predicting obesity in early adulthood from childhood and parental obesity. Int J Obes. 2003;27(4): 505-13. https://doi.org/10.1038/sj.ijo.0802251.

3. Datar A, Nicosia N. Assessing social contagion in body mass index, overweight, and obesity using a natural experiment. JAMA Pediatr. 2018; 172(3):239-46. https://doi.org/10.1001/jamapediatrics.2017.4882.

4. Sothern MS. Obesity prevention in children: physical activity and nutrition. Nutrition. 2004;20(7-8):704-8. https://doi.org/10.1016/j.nut.2004.04.007.

5. Tremblay MS, LeBlanc AG, Kho ME, et al. Systematic review of sedentary behaviour and health indicators in school-aged children and youth. Int J Behav Nutr Phys Act. 2011;8(1):1-22. https://doi.org/10.1186/1479-5868-8-98.

6. Janssen I, LeBlanc AG. Systematic review of the health benefits of physical activity and fitness in school-aged children and youth. Int J Behav Nutr Phys Act. 2010;7(1):40. https://doi.org/10.1186/1479-5868-7-40.

7. Asirvatham J, Thomsen MR, Nayga RM, Goudie A. Do fast food restaurants surrounding schools affect childhood obesity? Econ Hum Biol. 2019;33:12433. https://doi.org/10.1016/j.ehb.2019.01.011. 
8. Davis B, Carpenter C. Proximity of fast-food restaurants to schools and adolescent obesity. Am J Public Health. 2009;99(3):505-10. https://doi.org/1 0.2105/AJPH.2008.137638.

9. Bauman AE, Reis RS, Sallis JF, Wells JC, Loos RJF, Martin BW. Correlates of physical activity: why are some people physically active and others not? Lancet. 2012;380(9838):258-71. https://doi.org/10.1016/S0140-6736(12)60735-1.

10. Jin H, Lu Y. The relationship between obesity and socioeconomic status among Texas school children and its spatial variation. Appl Geogr. 2017;79: 143-52. https://doi.org/10.1016/j.apgeog.2016.12.008.

11. Macdonald L, Olsen JR, Shortt NK, Ellaway A. Do 'environmental bads' such as alcohol, fast food, tobacco, and gambling outlets cluster and co-locate in more deprived areas in Glasgow City, Scotland? Heal Place. 2018:51:224-31. https://doi.org/10.1016/j.healthplace.2018.04.008.

12. Maguire ER, Burgoine T, Penney TL, Forouhi NG, Monsivais P. Does exposure to the food environment differ by socioeconomic position? Comparing area-based and person-centred metrics in the fenland study, UK. Int J Health Geogr. 2017;16(1):33. https://doi.org/10.1186/s12942-017-0106-8.

13. Swinburn BA, Sacks G, Hall KD, McPherson K, Finegood DT, Moodie ML, et al. The global obesity pandemic: shaped by global drivers and local environments. Lancet. 2011;378(9793):804-14. https://doi.org/10.1016/S0140-6736(11)60813-1.

14. Niu L, Hoyt LT, Pachucki MC. Context matters: adolescent neighborhood and school influences on young adult body mass index. J Adolesc Health. 2019;64(3):405-10. https://doi.org/10.1016/j.jadohealth.2018.09.024.

15. Yang Z, Phung $H$, Hughes AM, Sherwood S, Harper E, Kelly P. Trends in overweight and obesity by socioeconomic status in year 6 school children, Australian Capital Territory, 2006-2018. BMC Public Health. 2019;19(1):1512. https://doi.org/10.1186/s12889-019-7645-9.

16. Andrea SB, Hooker ER, Messer LC, Tandy T, Boone-Heinonen J. Does the association between early life growth and later obesity differ by race/ ethnicity or socioeconomic status? A systematic review. Ann Epidemiol. 2017;27(9):583-92.e5. https://doi.org/10.1016/j.annepidem.2017.08.019.

17. Kim Y, Landgraf A, Colabianchi N. Living in high-SES neighborhoods is protective against obesity among higher-income children but not lowincome children: results from the healthy communities study. J Urban Heal. 2020;97(2):175-90. https://doi.org/10.1007/s11524-020-00427-9.

18. Villa-Caballero L, Caballero-Solano V, Chavarría-Gamboa M, et al. Obesity and socioeconomic status in children of Tijuana. Am J Prev Med. 2006;30(3):197203. https://doi.org/10.1016/j.amepre.2005.10.023.

19. Omorou AY, Manneville F, Langlois J, et al. Physical activity rather than sedentary behaviour is socially determined in French adolescents with overweight and obesity. Prev Med (Baltim). 2020;134:106043. https://doi. org/10.1016/j.ypmed.2020.106043.

20. Drewnowski A. Obesity, diets, and social inequalities. Nutr Rev. 2009; 67(SUPPL. 1):S36-9. https://doi.org/10.1111/j.1753-4887.2009.00157.x.

21. Obépi Roche. Enquête Épidémiologique Nationale Sur Le Surpoids et I'obésité:; 2012. https://presse.inserm.fr/wp-content/uploads/2012/10/ obepi_2012.pdf. Accessed 9 Jul 2020

22. Institut National de la Statistiques et des Etudes Economiques. Dossier Complet - Département Des Bouches-Du-Rhône (13).; 2020. https://www. insee.fr/fr/statistiques/2011101?geo=DEP-13\#consulter-sommaire.

23. Ly ST, Riegert A. COMMENT L'ÉCOLE AMPLIFIE LES INÉGALITÉS SOCIALES ET MIGRATOIRES ? Mixité Sociale et Scolaire et Ségrégation Inter-et IntraÉtablissement Dans Les Collèges et Lycées Français. http://www.cnesco.fr/ wp-content/uploads/2016/09/SegregationFrance1.pdf. Accessed 22 Jul 2020.

24. Kuczmarski R, Ogden C, Guo S, et al. CDC growth charts for the United States: methods and development. Vital Heal Stat. 2000;2002, 11(246) https://www.cdc.gov/growthcharts/2000growthchart-us.pdf.

25. Guignon N, Delmas M, Fonteneau L. En 2017, Des Adolescents Plutôt En Meilleure Santé Physique Mais plus Souvent En Surcharge Pondérale.; 2019. https://drees.solidarites-sante.gouv.fr/sites/default/files/er1122.pdf.

26. Luiggi M, Travert M, Griffet J. Temporal trends in sports participation among adolescents between 2001 and 2015: a French school- and territory-based study. Int J Environ Res Public Health. 2018;15(7):1335. https://doi.org/10.33 90/ijerph15071335.

27. Décret N²019-351 Du 23 Avril 2019 Relatif à La Composition Des Repas Servis Dans Les Restaurants Collectifs En Application de l'article L. 230-5-1 Du Code Rural et de La Pêche Maritime. https://www.legifrance.gouv.fr/affichTexte. do?cidTexte=JORFTEXT000038403867\&categorieLien=id. Accessed 22 Jul 2020.

28. Craig CL, Marshall AL, Sjöström M, et al. International physical activity questionnaire: 12-country reliability and validity. Med Sci Sports Exerc. 2003: 35(8):1381-95. https://doi.org/10.1249/01.MSS.0000078924.61453.FB.
29. Armstrong T, Bull F. Development of the World Health Organization global physical activity questionnaire (GPAQ). J Public Health (Bangkok). 2006;14(2): 66-70. https://doi.org/10.1007/s10389-006-0024-x.

30. Lamprecht M, Bürgi R, Stamm H. Sport Suisse; 2014. p. 2014.

31. Ainsworth BE, Haskell WL, Herrmann SD, et al. 2011 compendium of physical activities: a second update of codes and MET values. Med Sci Sports Exerc. 2011;43(8):1575-81. https://doi.org/10.1249/MSS.0b013e31821ece12.

32. Lear SA, Hu W, Rangarajan S, Gasevic D, Leong D, lqbal R, et al. The effect of physical activity on mortality and cardiovascular disease in 130000 people from 17 high-income, middle-income, and low-income countries: the PURE study. Lancet. 2017;390(10113):2643-54. https://doi.org/10.1016/S0140-6736(17)31634-3.

33. Efron B. An Introduction to the Bootstrap - 1st Edition - Bradley Efron - R.J. https://www.routledge.com/An-Introduction-to-the-Bootstrap/Efron-Tibshira ni/p/book/9780412042317. Accessed 6 Jul 2020.

34. Sanchez-Vaznaugh EV, Weverka A, Matsuzaki M, Sánchez BN. Changes in fast food outlet availability near schools: unequal patterns by income, race/ ethnicity, and Urbanicity. Am J Prev Med. 2019;57(3):338-45. https://doi. org/10.1016/j.amepre.2019.04.023

35. Li Y, Du T, Huff-Corzine L, Johnson K, Noyongoyo B. Where is the fruit? Multidimensional inequalities in food retail environments around public elementary schools. Child Care Health Dev. 2019;45(4):cch.12671. https://doi. org/10.1111/cch.12671.

36. Klugman J, Lee JC. Social closure, school socioeconomic composition, and inequality in college enrollments. Soc Sci Res. 2019;80:156-85. https://doi. org/10.1016/j.ssresearch.2018.12.021.

37. Palardy GJ. Differential school effects among low, middle, and high social class composition schools: a multiple group, multilevel latent growth curve analysis. Sch Eff Sch Improv. 2008;19(1):21-49. https://doi.org/10.1080/ 09243450801936845

38. Bégué $P$, Gangeot-Keros B-P, Hermange $P$, et al. La médecine scolaire en France. Bull Acad Natl Med. 2017;201(7-9):957-72. https://doi.org/10.1016/ s0001-4079(19)30413-3.

39. Sherry B, Jefferds ME, Grummer-Strawn LM. Accuracy of adolescent selfreport of height and weight in assessing overweight status: a literature review. Arch Pediatr Adolesc Med. 2007;161(12):1154-61. https://doi.org/10.1 001/archpedi.161.12.1154.

40. Bowring AL, Peeters A, Freak-Poli R, Lim MSC, Gouillou M, Hellard M. Measuring the accuracy of self-reported height and weight in a community-based sample of young people. BMC Med Res Methodol. 2012; 12(1). https://doi.org/10.1186/1471-2288-12-175.

41. Allison C, Colby S, Opoku-Acheampong A, Kidd T, Kattelmann K, Olfert MD, et al. Accuracy of self-reported BMI using objective measurement in high school students. J Nutr Sci. 2020;9:e35. https://doi.org/10.1017/jns.2020.28.

42. Olfert MD, Barr ML, Charlier CM, Famodu O, Zhou W, Mathews A, et al. Selfreported vs. measured height, weight, and BMI in young adults. Int J Environ Res Public Health. 2018;15(10):1-9. https://doi.org/10.3390/ijerph15102216.

43. Lipsky LM, Haynie DL, Hill C, Nansel TR, Li K, Liu D, et al. Accuracy of selfreported height, weight, and BMI over time in emerging adults. Am J Prev Med. 2019;56(6):860-8. https://doi.org/10.1016/j.amepre.2019.01.004.

44. Stommel M, Osier N. Temporal changes in bias of body mass index scores based on self-reported height and weight. Int J Obes. 2013;37(3):461-7. https://doi.org/10.1038/ijo.2012.67.

45. Rivière F, Widad FZ, Speyer E, Erpelding ML, Escalon H, Vuillemin A. Reliability and validity of the French version of the global physical activity questionnaire. J Sport Heal Sci. 2018;7(3):339-45. https://doi.org/10.1016/j. jshs.2016.08.004

46. Bull FC, Maslin TS, Armstrong T. Global physical activity questionnaire (GPAQ): nine country reliability and validity study. J Phys Act Health. 2009; 6(6):790-804. https://doi.org/10.1123/jpah.6.6.790.

47. Cleland CL, Hunter RF, Kee F, Cupples ME, Sallis JF, Tully MA. Validity of the global physical activity questionnaire (GPAQ) in assessing levels and change in moderate-vigorous physical activity and sedentary behaviour. BMC Public Health. 2014;14(1):1-11. https://doi.org/10.1186/1471-2458-14-1255.

48. Gorzelitz J, Peppard PE, Malecki K, Gennuso K, Nieto FJ, Cadmus-Bertram L. Predictors of discordance in self-report versus device-measured physical activity measurement. Ann Epidemiol. 2018;28(7):427-31. https://doi.org/10.1 016/j.annepidem.2018.03.016.

\section{Publisher's Note}

Springer Nature remains neutral with regard to jurisdictional claims in published maps and institutional affiliations. 